\title{
An Analysis of the Characteristics of Thai Slow Tourist Along the Khmer Cultural Routes in Thailand Using Factor Analysis Techniques
}

\author{
Juthathip Sutthitep \\ Ph.D candidate: Tourism and Hospitality Innovation Management, Faculty of Management Sciences \\ KhonKaen University, juthatipkik99@yahoo.com \\ Supalak Akkaranggoon \\ Principal advisor: Tourism Department, Faculty of Management Sciences \\ KhonKaen University; supakk@kku.ac.th

\section{Supannee Ungpansattawong} \\ Co-advisor: Statistics Department, Faculty of Science, KhonKaen University \\ supunnee@kku.ac.th
}

Doi:10.5901/mjss.2016.v7n2p418

Abstract

This research was aimed at studying the characteristics of Thai tourist who were taking a slow trip along the Khmer cultural routes in Thailand. It focuses on two aspects of touring: touring characteristics and touring behaviors. The framework of this study is based on a review of the existing literature in the related fields. It was observed that taking slow trip results in an alteration with regards to the tourists' behaviors and the forms of tourism. To be more specific, slow trip takers tend to take their time while traveling, and this enables them to appreciate more about the places along the way. Furthermore, slow trips can help tourists to gain a better understanding about the places they are visiting (Ranee Esichaikul \& Chatchapol Songsungthonwong, 2012). Obtaining sufficient information about the characteristics of this type of tourists can help tourism entrepreneurs to prepare goods and services that appropriately serve the needs of this particular group of tourists. This research is confined to the quantitative research discipline. Questionnaires were distributed to Thai slow trip takers and the data was analyzed using factor analysis. The factor analysis results help to classify the slow trip takers into 12 groups based on their characteristics as follows: touring objectives, perception and expectation about the tour, knowledge and experience, touring activities, touring flexibility, quest to learn new things \& the state of being an explorer, cultural differences, learning skills, concerns about the well-being of nature, awareness of conservationism, selection of accommodation, and curiosity.

Keywords: Slow tourists, Factor Analysis, Sustainable Tourism

\section{Introduction}

The rapid growth of tourism and infra-structure affected the environment and natural resources including the tourism vehicle that caused an increase of carbon hydroxide in the air. Research results in tourism industry showed that transportation released the highest amount of carbon hydroxide at 87 per cent, followed by 9.1 per cent from the accommodations and 4 per cent from tourism activities respectively ( Peters,2007) [2]. These causes affected the climate change, environment and sea level. From these negative tourism impacts, researcher and tourism policy makers were interested in studying the tourism's impact on environments and inhabitants (Lea,1988) [3] by focusing on sustainable development in tourism, and this led to a creation of new type of tourism called Slow Tourism.

Slow Tourism was a result from an anti-fast food in Italy in 1986. This event aimed to protect nutritious consumption, preserve local cuisine tradition and support local livestock affecting local ecosystem, consequently, slow food trend occurred. This effort was put into stage from international supports with 100,000 members from 150 countries (Slow Food International, 2014) with 2,000 convey slow food networks. These communities followed slow food principle by preserving cuisine culture and tradition, for example cooking, and traditional cuisine production and consumption (Petrini, 2003). The integration of slowness principle with tourism created change in travel behavior and types of tourist as Ranee Isichaikul and Chatchapol Songsuntornwong (2012) proposed that slow tourism helped tourists to experience attractions in details which cannot be seen in the rapid case. The tourism attractions should offer, invite and create 
program and activities based on the route, for example trekking, cycling in rural sites, visiting ancient community and interacting with local people in the tourism activities. This slow tourism was considered new target market for tourists who needed new experience. Characteristics of this type of tourist were indicated in this research. This slow tourist had positive effect on environmental, social and economical contexts in the visited community. All tourism stakeholders should disseminate knowledge about sustainable tourism used in environment, social and economic including creating campaign in environmental friendly tourism and social responsibility.

This investigation of Thai slow tourism along the cultural routes in Thailand is aimed to obtain information about the forms of slow touring and the behavioral patterns of the slow tourists. In addition, it seeks to accomplish the following: 1) to explain what makes the slow tourists different from other types of tourists, and 2) to obtain information that can be used to identify slow tourists. The data obtained from this research could assist entrepreneurs who wish to become more responsive to the specific needs of the slow tourists.

\section{Review of Related Literatures}

\subsection{Slow Tourism}

Studying research literature, related to slow tourism, it is attributed to a desire to reduce the problems that have an impact on the environment when living one's own life. Slow tourism tends to minimize the trip distance resulting in the consumption of less fuel. It involves the least amount of co2 emissions into the air, but allowing tourists to still fully enjoy their trip. In Italy, the idea of slow tourism has been gaining increased public interest since 1986. In the same year, there was a public demonstration against the opening of a McDonald's restaurant, the American fast-food chain. The demonstration called for people to support the eating of healthy or slow food which is more beneficial to health as compared to fast-food. That fast-food strike also echoed the global needs for people to live slower lives. The idea of a slow life was disseminated into different working fields, including slow traveling; an alternative tourism that cares for the sustainability of the local culture, economy, community, and environment (Conway \&Timm, 2010).

Dickinson and Lumsdon (2010:75) stated that slow tourism is an alternative tourism that is coherent with a system of communication. Furthermore, it generates many different forms of tourism that can be classified as follows:

Table 1: The differences between mainstream tourism and slow travel

\begin{tabular}{|l|l|}
\hline Contemporary tourism & Slow travel \\
\hline Speed transit & Slow travel times \\
\hline Prevailing modes of the car and airline & Wider range of modes including bus and train \\
\hline Immediacy & Slowness \\
\hline Resource intensive & Resource reduction \\
\hline Journey is corridor & journey is the thing \\
\hline Consumption of many attractions & Localness \\
\hline Maxi zing visits & Staying awhile \\
\hline High-carbon & Low carbon \\
\hline Commoditization & De-commoditization \\
\hline Standardized hospitality dominates & Slow food and beverage \\
\hline
\end{tabular}

Source: Dickinson \&Lumsdon (2010: 191)

However, Chondarong Tongsong (2015) pointed that slow tourism should consist of 10 concepts (10 Slow: 10S) as follows. 1) Slow Activity means doing longer activities at each tourist spot. 2) Slow Logistic refers toleisure, safe and environmentally friendly travel. 3) Slow Food is delicate cooking using fresh, clean and safematerials. 4) Slow Stay is to have more overnights at a tourist area and do suitable touristic leisure activities.5) Slow Place/City refers to residing at a community tourist area or a peaceful small town with no pollution.6) Slow Money is a fair division of expenses between travel enterpreneur and tourists. 7) Slow Development entails small-scale development that supports tourist activities. 8) Slow Accommodation is about peaceful, clean, and safe accommodations with good environmental management. 9) Slow Life refers to spending time peacefully in nature and to a rustic life style. 10) Slow Energy refers to tourist activities that save energy. 


\subsection{Slow Tourism Activities}

Dickinson \&Lumsdon (2010) explained that slow tourism can be a trip that is involved with mainly with travelling, basically a short distance, or it can be making stops for different activities at different tourist attractions that are spread along the route of the trip. Moreover, this kind of slow trip may be seen in the following forms: 1) walking tourism, 2) cycling tourism, and/or 3) train tourism. Taking a train can be a tour on its own merit as you can enjoy the ride and see the impressive scenery that commuting by train brings you. Also, it can be a trip for touring when taking a train as a means to help you reach your tourism destination. Taking a train trip speaks to the idea of Low-carbon Tourism due to the fact that the trains are vehicles that produce the fewest amounts of c02 emissions compared to other forms of transportation, such as airplanes and cars.

Ranee Esichaikul and Chatchapol Songsoonthorn (2012) view that slow tourism encourages exercising, eating local foods, learning about local cultures, and geographically studying about the existing seas and mountains. It exempts tourists from lives of depression, congestion, and loud noises associated with cities. Tourists therefore, are given chance to rejuvenate their physical and mental health through relaxing activities, such as, rowing canoes, rafting, and trekking through forests. Similar ideas were found in Esichaiku (2013) regarding the extent that cultural tourism encourages slow mobility among tourists. Some examples of cultural tourism can be seen from visiting historical parks via trains or trailers, cycling through cultural villages, visiting temples \& community museums, chatting with monks in a temple, learning about herbs in the temples, or sailing a boat in the channel. Other activities include inspecting light \& sound performances, interacting with the local people, exploring around community market of the walking street, or practicing local handicrafts.

As described in Lee, Scott and Packer, (2014) popular slow tourism activities involving food preparation include buying foods from the sub-scaled producers, eating local foods, and shopping local products in a local market. In addition, whenever possible, slow tourists design flexible schedules for their trip so that they can spend longer time at one place. By doing this, it helps to increase the interacting time with the locals. It was also found that slow tourists prefer to stay in an apartment with a kitchen and cooking utensils, so that they will be able to cook. Slow tourists love to buy cook books and are especially interested in learning to cook local dishes.

Based on the review of literature above, it can be concluded that the factors which contribute to slow tourism are as follows: 1) the vehicles used in the trip, 2) the involvement in the activities available at tourist site, and 3) the time spent at each tourist site. The combination of these factors generates slow tourism.

Given that slow tourism has now been developed more concretely, the business can attract huge sums of foreign currency to Thailand. Some crucial keys to the development of Thailand's slow tourism rely upon on taking strict control of the standards of services by preventing over-exploitation and the deterioration resources. This can be accomplished by strengthening measures regarding the capacity of carrying and zoning for tourism. Following these measures is what is needed to get Thailand to "stand out" regarding its tourism business for the future. Based on its latent capacities with respect to slow tourism, the future for Thailand is promising with regard to retaining its status.

\subsection{Slow tourists}

The connection between slow tourism and places that tourists are visiting is based on the following: 1) how well the tourist hub encourages the tourists to see the routine of local life, 2) how attractive the site is in making tourists want to try its local foods, and 3) how well the tourist are encouraged to become cultural experts about the place they are visiting. From what have been said thus far, it can be concluded that the key concept of slow tourism is that it is a kind of tourism that conforms to the local practices to reflect the slowness of the community, such as slow foods and a slow city. Slow tourism should have the following components: 1) Its main activities should involve transportation and commuting to new places. 2) Slow tourism should be used for sustainable tourism. 3) Statements should be made showing why it is worthwhile to take a slow trip in the tourist area. Furthermore, these statements should be emphasized and displayed on the labels of goods and services.

Yurtseven and Kaya (2011) classified "slow tourists who take a slow tour in a slow city" by basing their classification on a method developed by Cittaslow. Based on this classification, three groups of slow tourists are presented: 1) Dedicated Slow Tourists, 2) Interested Slow Tourists, and 3) Accidental Slow Tourists. More details of each type of tourist are now discussed. The Dedicated Slow Tourists tend to do the following: 1) be open to the slow tourism experience, be interested in exploring, and be aware of cultural diversities \& local identities; 2) be educated and wellequipped with knowledge regarding cultural backgrounds, as well as be knowledgeable and understand the Principle of Slowness; 3) organize one's own trip by one's self; 4) possess high expectations about the place(s) they are visiting; and 5) be joyful to try the foods that are eco-gastronomic. Similar ideas about slow tourists can be observed in 
ChaninYoopetch (2012:6) who postulates that slow tourists should incorporate the following characteristics: 1) to like to take in new experiences about the visiting place without hurrying, to be eager to find new things in the culture and new places that are different from one's own; 2) to become knowledgeable and interested in culture and the principle of slow life; 3 ) to be independently selective in deciding on where to visit without having to follow the crowd or to be free from the illusion of the reputation of the tourism destination; 4) to have high expectations about the places they are visiting \& the new things they can learn from the visit; and 5) to have a desire to taste foods or products typical to the visiting area.

In addition, Salvo (2013) makes a comparative study about the characteristics of repellent tourists and slow tourists. The objectives of Salvo's study were to analyze the results of slow tourism and its effectiveness in attracting new batches of slow tourists. It was observed that the slow tourists were able to absorb new touring experiences better than the repellent ones. Salvo's research shows the characteristics of slow tourists. It emphasizes the fact that slow tourism is a brand new form of tourism that affects consumption and the commute. Salvo has listed key differences between slow tourists and the lay-tourists as follows: 1) Slow tourists are quality oriented but not quantity-oriented travelers. Since they usually seek for great content trips rather than symbolic trips, they hold that holidays are for privacy and that taking holiday vacation is a socially uplifting moment. 2) With positive incentives, slow tourists can absorb new cultural experiences via their trip. 3) Slow tourists are good consumers, they make careful selections regarding the destination and they know upon arrival what they should or should not do at their selected destination. 4) Slow tourists look for the true working value or concept of the locals and tend to stay away from the commercial environment. 5) Slow tourists are highly responsible and are very sensitive regarding the consumption of delicate and rare resources. Also, they are good moral practitioners who are willing to follow social moral prescription. 6) Overall, slow tourists are different from lay tourists with regard to their behaviors, slowness, and the selections for commute forms and traveling destinations.

It is righteous to say that slow tourists are one of the factors that have born slow tourism forward, and slow tourists have been influential in developing the tourist attractions toward their sustainability (Yurtseven\& Kaya, 2011).

The development of slow tourism should be taken into account by considering the wise use of resources so as to avoid the evolution of future problems. As its history has shown, the business of Thai tourism has mainly emphasized the expansion of its business without paying attention to preserving unique local cultures and environments. As a result, many problems have arisen from these acts of carelessness. Slow development, which is a development that cares for the local culture and the preservation of the environment, should be introduced side by side with the improvement of slow tourism.

\section{Research Methodology}

This research is based on the qualitative research discipline. Questionnaires were distributed to groups of Thai tourists taking their trip along Khmer cultural routes covering the areas of four provinces namely; Nakhonratchsima, Buriram, Surin, and Srisaket. The eligible participants for the study were those who had made at least a two-night stay on their trip. Accordingly, questionnaires have been used for data collection because they are a more commonly used tool for data collection in research related to the tourism and hotel industries. Questionnaires can be made very specific, are easy to prepare, and can save time and cost while enabling large scale of data collection. Furthermore, they are appropriate for different types of research (Aswin Sangpikul, 2013, 176).

\subsection{Data Collection}

Sets of questionnaires were distributed to 385 tourists who were taking a trip along the Khmer Cultural Routes covering the areas in 4 provinces namely: Nakhonratchsima, Buriram, Surin, and Srisaket. The samples were selected using Probability Sampling, and the sample size was gauged using the formula proposed by Cochran. (cited in Supanee Ungpanyasattawong: 2011:43). The researcher tried out the corrected questionnaires with a group of 30 tourists who held similar qualities as the target group. The validity of the data derived from the questionnaires was analyzed using Cronbach's Method to obtain Cronbach's Alpha Coefficient (Luan Saiyod \& AngkanaSaiyod: 2000). It was found from this analysis that the reliability of Co-efficient Alpha was at 0.973 showing that the questionnaires had high level of reliability.

\subsection{Data Analysis}

Factor analysis was used for the classification of variables. Correlation was also analyzed in order to test the cross relationship among different variables using a statistic named KMO (Kaiser-Meyer-Olkin). This statistic is essential for 
evaluating the appropriateness of data before it is used in Factor Analysis which, in this research, is important to the classification of the slow tourists. The three steps of data analysis are shown in the diagram below:

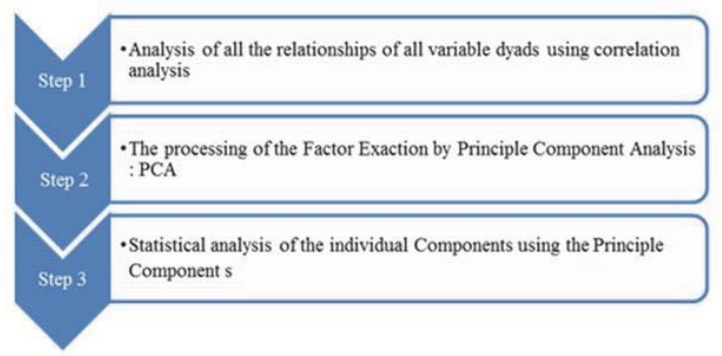

\section{Research Results}

Data from the questionnaire was found to have a Kaiser-Myer-Olkin Measure (KMO) value of 0.902 which is higher than 0.5 and is rounding up to 1 . This value also shows that the obtained data is appropriate to be used for Factor Analysis. The Bartnett's Test of Sphericity shows a statistical significance of less than 0.05 , which means that the factors stated in the questionnaire can efficiently represent the factors that affect the characteristics of the slow tourists. The result of factor analysis using Principal Component Analysis (PCA), turning its axis using the Varimx method, shows 12 factors or around 62 variables that affect the state of being slow tourists (See Tables 2). Naming these 12 factors was based on their overall meaning and on their related variables. Priority of naming was given to variables with the highest Factor Loading Value. The twelve factors are listed below:

Component 1: The Purposes of Tourism are initial needs for a person to take a trip. This is basically due to a desire to get away from a hectic life and to be exposed to peace and placidity. Taking a trip is considered to be selfrewarding. In addition, taking a trip somewhere is an eye-opening experience that provides chances to learn about new people, cultures, and new ways of life.

Component 2: Relaxation \& Leisure Type/Tourist Perception. This component shows that slow tourists have their personal expectation about the place they are visiting. They tend to perceive things via sensing and focusing on the existing evidence about the tourist attraction.

Component 3: Knowledge and Experience. Slow tourists are those who obtain knowledge and experiences from their trip via language and cultural learning, costumes, foods, and having interactions with the local people.

Component 4: Tourist Activities. Slow tourists like to take part in activities during their trips. Some examples of activities related to daily life are looming, riding elephants, carving silver wear, and growing rice. In addition, slow tourists also enjoy cultural events and the traditions of the locals.

Component 5: Touring Flexibility. A trip with flexibility is a trip in which the designed program can be changed, for instance, changing in number of days for touring. Slow tourists do not specify number of places they are going to visit each day of their trip.

Component 6: Novelty and Seekers/Food. Slow tourists are those who long for something new and like to be explorers, such as being a gourmet or an epicurean.

Component 7: Cultural Conversation. Slow tourists regard cultural diversity as something rewarding for their trip. Consequently, this type of tourists is very careful not to behave improperly, or to say something that may sound offensive or to be insulting to the local ways of life and culture.

Component 8: Skill Learners. Slow tourists possess high learning skills. They learn things by themselves via reading signs, brochures, leaflets and websites. They usually have good interactions with tour guides.

Component 9: Environmental Responsibility. Slow tourists are people who care for environment. They usually select a tour that has the lowest effect on the environment. They are concerned with classifying their trash and leaving it properly in the litter box available.

Component 10: Being a Conservationist. Slow tourists have strong concern about preserving the natural resources and having a correct perception about conservation. They don't think that conservation is concerned with collecting ancient products, animal corpses, or rare species of plants and animals. Neither do they think that writing or scratching letters or statements on the walls, stones, nor are trees in tourist attractions memorable reminders of their visits.

Component 11: Local Economic Support when Selecting Accommodation. In order to give support to the local 
economy, slow tourists prefer to stay in small places owned by the local rather than in big hotels. Their preferable choices are home stays, resorts, or serviced apartments, but not the internationally recognized hotel chains.

Component 12: Curiosity and Tourism Interpretation. With their quest to know about the places they will visit, slow tourists often hire local tour guides or tourism officers to give descriptions about the history or origins of the places they are visiting.

From the previously stated factor analysis, it can be seen that the characteristics of the Thai slow tourists consist of the following components: touring objectives, expectations \& perceptions about touring, knowledge and experience, touring activities, touring flexibility, desires for experiencing something new \& the state of being an explorer, an appreciation of cultural diversity, learning skills, a desire to care for the environment, being a conservationist, the selection of accommodation, and curiosity, respectively.

Table 2. The Components of Slow Tourists' Behaviors Based on Factor Analysis Results

\begin{tabular}{|c|c|c|}
\hline Components & Items & $\begin{array}{l}\text { Factor } \\
\text { loading }\end{array}$ \\
\hline \multirow[t]{12}{*}{ Purposes of Tourism } & - $\quad$ A preference for gaining peace and placidity. & .845 \\
\hline & $\begin{array}{ll}- & \text { A desire to live away from daily life and occupational depressions. }\end{array}$ & .843 \\
\hline & - $\quad$ A wish to get away from a hectic life. & .817 \\
\hline & - $\quad$ To obtain freedom. & .804 \\
\hline & - $\quad$ A need for relaxation and rest. & .759 \\
\hline & - $\quad$ To reward one's own-self. & .707 \\
\hline & $\begin{array}{ll}\text { - } & \text { To meet new people and have new experiences. }\end{array}$ & .687 \\
\hline & - $\quad$ To experience the adventurous side of life. & .686 \\
\hline & - $\quad$ To enjoy a lot of different places and activities. & .662 \\
\hline & - $\quad$ To earn experience and take part in local cultures and activities. & .528 \\
\hline & - $\quad$ To learn about new cultures and new ways of life. & .478 \\
\hline & - $\quad$ To freely organize one's own time when visiting a place. & .416 \\
\hline \multirow[t]{15}{*}{ Relaxation and Leisure Type } & $\begin{array}{l}\text { - To believe that taking a trip is a chance "to recharge the batteries of } \\
\text { life". }\end{array}$ & 670 \\
\hline & - $\quad$ To take a trip that makes you understand different ways of life. & .652 \\
\hline & - $\quad$ To take a trip that a trip brings you joy and pleasure. & .649 \\
\hline & $\begin{array}{ll}\text { - To take a trip that is a way of learning new things that are different from } \\
\text { your local. }\end{array}$ & 641 \\
\hline & $\begin{array}{l}\text { - A desire to obtain knowledge and to have an "eye-opening experience" } \\
\text { from the things that have been learned from the trip. }\end{array}$ & 628 \\
\hline & - $\quad$ To take a trip that rehabilitates you physically and mentally. & .628 \\
\hline & $\begin{array}{l}\text { - } \begin{array}{l}\text { To strictly follow the rules and directions posted by officials in the } \\
\text { places that you visit. }\end{array} \\
\end{array}$ & 581 \\
\hline & $\begin{array}{l}\text { - To be always aware and cautious about the "after-effects" that follow } \\
\text { after any activities that you do on your trip. }\end{array}$ & .559 \\
\hline & $\begin{array}{l}\text { - To prefer to buy local products that are sold at the attractions you are } \\
\text { visiting. }\end{array}$ & .527 \\
\hline & - $\quad$ To like to travel using your own car. & .502 \\
\hline & $\begin{array}{l}\text { - } \begin{array}{l}\text { To take part in religious activities. For example, to do meditation and to } \\
\text { offer food to monks. }\end{array} \\
\end{array}$ & .469 \\
\hline & $\begin{array}{l}\text { - To take part in food festivals and in other cultural festivals. } \\
\text {. }\end{array}$ & .456 \\
\hline & $\begin{array}{l}\text { - To become knowledgeable about the history and origins of the places } \\
\text { you are visiting. }\end{array}$ & 435 \\
\hline & $\begin{array}{l}\text { - To immediately notify tourism officials regarding cases the misconduct if } \\
\text { you spot someone breaking the tourism rules. }\end{array}$ & 409 \\
\hline & $\begin{array}{l}\text { - To always conduct research about tourism problems prior to the starting } \\
\text { of your trip and in between trips. }\end{array}$ & 405 \\
\hline \multirow[t]{3}{*}{ Knowledge \& Experiences } & $\begin{array}{ll}- & \text { To broaden your knowledge by talking with the local people. }\end{array}$ & .757 \\
\hline & - $\quad$ To learn about the local culture via foods, language, and costumes. & .724 \\
\hline & - To often obtain new perspectives on life after taking a trip. & .723 \\
\hline
\end{tabular}




\begin{tabular}{|c|c|c|c|}
\hline \multirow[t]{4}{*}{ Components } & \multicolumn{2}{|c|}{ Items } & \multirow{2}{*}{$\begin{array}{l}\text { Factor } \\
\text { loading } \\
.563 \\
\end{array}$} \\
\hline & & To get to know more about yourself after taking a trip. & \\
\hline & & $\begin{array}{l}\text { To always manage to turn off the switches before leaving the room } \\
\text { even though the room you are staying in is equipped with an automatic } \\
\text { electricity cut-out. }\end{array}$ & .482 \\
\hline & & $\begin{array}{l}\text { To prefer to walk around rather than using other vehicles to wander } \\
\text { around the tourist attractions. }\end{array}$ & .456 \\
\hline \multirow[t]{7}{*}{ Tourist Activities } & & $\begin{array}{l}\text { To take part in activities connected to a reflective way of living, such as } \\
\text { working on the loom, riding elephants, carving silverware, and growing } \\
\text { rice. }\end{array}$ & .705 \\
\hline & & $\begin{array}{l}\text { To take part in environmental preservation activities, such as planting } \\
\text { trees, building irrigation systems, and releasing fish. }\end{array}$ & .667 \\
\hline & - & To learn to cook local foods at the places you are visiting. & .642 \\
\hline & & $\begin{array}{l}\text { To use local public services for commuting which are available in the } \\
\text { tourist areas. }\end{array}$ & .574 \\
\hline & - & To prefer to have local tour guides to lead you on the trip. & .487 \\
\hline & & $\begin{array}{l}\text { To often buy cooking ingredients that are available at the local tourist } \\
\text { attraction. }\end{array}$ & .452 \\
\hline & & $\begin{array}{l}\text { To participate in local festivals, such as attending the Elephant Fair in } \\
\text { Surin, the Doklumduan Fair, the Gin Khoakhum Fair, and the Silk fair, } \\
\text { as well as climbing Phanomrung Mountain. }\end{array}$ & .429 \\
\hline \multirow[t]{8}{*}{ Flexibility in touring } & - & To make your vacation plans adjustable. & .649 \\
\hline & & $\begin{array}{l}\text { Not to have a specific plan as how many places to visit, or where to visit } \\
\text { on each day of your trip. }\end{array}$ & .605 \\
\hline & & $\begin{array}{l}\text { To like to go to places that usually have a lot of people and that have } \\
\text { been prepared for tourists to visit. }\end{array}$ & .556 \\
\hline & & $\begin{array}{l}\text { To take a trip by visiting as many places in the province as you can and } \\
\text { as quickly you possibly can is your favorite way of travelling. }\end{array}$ & .553 \\
\hline & & $\begin{array}{l}\text { To stop here and there during the trip, and to take the trip without being } \\
\text { in a hurry. }\end{array}$ & .539 \\
\hline & & $\begin{array}{l}\text { To be unconcerned with the number of places that you visit on each of } \\
\text { your trips because it does not matter to you. }\end{array}$ & .448 \\
\hline & & $\begin{array}{l}\text { To prefer to behave in ways that conform to the behaviors of the people } \\
\text { in the areas that you are visiting. }\end{array}$ & .425 \\
\hline & & $\begin{array}{l}\text { To prefer to go to the places where other people like to go, for example, } \\
\text { to go to the local markets and walking streets. }\end{array}$ & .378 \\
\hline \multirow[t]{3}{*}{ Novelty and Seekers } & - & To prefer to have foods that you are familiar with. & .697 \\
\hline & & $\begin{array}{l}\text { To prefer not to eat meals that are served in the local areas or tourist } \\
\text { attractions. }\end{array}$ & .666 \\
\hline & - & To often try foods and drinks that are locally available. & .650 \\
\hline \multirow[t]{2}{*}{ Cultural Conservation } & - & To think that cultural diversity makes your trip more interesting. & .565 \\
\hline & & $\begin{array}{l}\text { To believe that it is improper for tourists to insult others and/or to act } \\
\text { disrespectfully towards people of different cultures and their ways of } \\
\text { life. }\end{array}$ & .560 \\
\hline \multirow[t]{3}{*}{ Skill learners } & & $\begin{array}{l}\text { To use transportation services, such as, bicycles, service buses, and in- } \\
\text { farm service wagons. }\end{array}$ & .554 \\
\hline & & $\begin{array}{l}\text { To enjoy learning about your trip from signs, brochures, leaflets, and } \\
\text { websites. }\end{array}$ & .538 \\
\hline & & $\begin{array}{l}\text { To prefer to take a trip that has the least effect on the destruction of } \\
\text { resources, such as visiting sites with examples of ancient architecture } \\
\text { like temples, and Khmer castles. }\end{array}$ & .463 \\
\hline \multirow[t]{2}{*}{ Concerns for the Environment } & & $\begin{array}{l}\text { To prefer to take a trip that has the least effect upon the environment } \\
\text { and the community that is being visited. }\end{array}$ & .670 \\
\hline & & $\begin{array}{l}\text { To always separate types of garbage, and to properly discard them in } \\
\text { the places provided. }\end{array}$ & .646 \\
\hline Conservation & - & To believe that in order to conserve rare works of art and nearly extinct & .737 \\
\hline
\end{tabular}




\begin{tabular}{|l|l|c|}
\hline Components & Items & $\begin{array}{c}\text { Factor } \\
\text { loading }\end{array}$ \\
\hline & $\begin{array}{l}\text { animals it is best to accomplish this by collecting ancient works of art, } \\
\text { such as sculptures of the Buddha's head, and by collecting rare and } \\
\text { wild animal corpses. }\end{array}$ & .690 \\
\cline { 2 - 4 } & $\begin{array}{l}\text { To think that scratching and/or writing on rocks and trees in the tourist } \\
\text { areas are ways to commemorate your visit. }\end{array}$ & $\begin{array}{c}\text { To enjoy staying in small hotels, such as home stays, guesthouses, } \\
\text { serviced apartments, or hotels owned by local people, but not to enjoy } \\
\text { staying in famous hotel chains. }\end{array}$ \\
\hline Accommodation Selection & $\begin{array}{l}\text { To often have local tour guides or tourist officials to accompany you on } \\
\text { your trip and to explain the history the places that you visit. }\end{array}$ & .691 \\
\hline Learning Curiosity & Bartlett's Test of Sphericity Sig. & .000 \\
\hline & Kaiser-Meyer-Olkin measure of sampling adequacy & .902 \\
\hline & Total variance & $68.866 \%$ \\
\hline
\end{tabular}

\section{Conclusions}

This research shows that the characteristic of Thai slow tourists consists of 12 components namely; objective of touring, expectation and perception about touring, knowledge and experience, touring activities, touring flexibility, desire for something new \& the state of being an explorer, appreciation of cultural diversity, learning skills, caring for environment, being a conservationist, the selection of accommodation, and curiosity, respectively. It is sufficed to say that the set objectives of the tour results in the knowledge and experience which are the expectations of the visit. With clear visiting aims, slow tourists have a sharp focus on activities. They also project proper behaviors by learning to be one of the supporters that conserve the local culture and environment and they prefer to buy local products to support the local economy. In order for the goods and products to be correctly responsive to the specific needs of the slow tourists, supports from all stakeholders such as, tourists, entrepreneurs, resources owners, government, and academics are needed. The working principle for these people is how to wisely use the limited resources for their upmost benefits for the present and for the future.

\section{Discussion and Recommendations}

Based on the information previously discussed, sections of the government and entrepreneurs in businesses should promote slow tourism by implementing the following strategies:

Firstly, activities designed for each trip should encourage that a longer time period be spent at the site being visited. By so doing, the tourists will be able to fully acquire mental and physical relaxation. In addition, spending a longer time period at each tourist attraction encourages the spending of additional revenues and supports the flow of money to local businesses. It is, therefore, crucial for the activities, conducted at each of the tourist attractions, to be culturally and historically diverse. Furthermore, they should encourage learning for and among the tourists because this will make it worthwhile for the tourists to spend a longer time there. The activities should also reflect the local identity and should be tempting in order to get the tourists' attention.

Secondly, the accommodations, that encourage slow tourism, should be made appropriate for slow tourists who basically stay longer than 2 nights. Therefore, the accommodations should be diversified and there should be a variety of choices, such as home stays, farm stays, guesthouses, and serviced apartments. Also, hotels and resorts of different sizes should be included. A variety of accommodations can better serve the needs of the slow tourists with different economic backgrounds.

Thirdly, foods for slow tourism should be "slow foods" made from clean and well-selected ingredients. The ingredients should be obtained locally while the cooking methods and tastes should be original. Since slow foods are prepared using local ingredients, the local farmers should be respectively encouraged to produce highly hygienic agricultural products. As a consequence, the process speeds up the flow of money to local businesses. It is also a wise way to conserve the culture of the food for the next generation.

Finally, the vehicles, used for slow tourism, should be safe and environmentally friendly. It is recommended that the modes of transportation utilized by slow tourism should use clean energy. Tourists should be encouraged to use public transportation, such as trains and buses. The locally-owned vehicle services should also be supported because 
this would be a successful way to bring in more income for the local entrepreneurs and communities.

If the clear development plans for slow tourism are implemented, it can be concluded that Thailand can become a successful and sustainable hub for slow tourism. Plans for this development should be drafted by keeping in mind the diversity of the local cultures. Most importantly, the master key is the cooperation of all stakeholders. This cooperation has the ability to unlock the successful development of Thailand's slow tourism industry so that the utmost benefits can be derived and the outcomes can be sustainable.

\section{Acknowledgement}

This research article is part of the research entitled classification of Thai slow tourist along the Khmer cultural route in Thailand. This article cannot be completed without a great support from Assistant Professor Dr. Supalak Akkaranggoon for her valuable comments and editing. Researcher is deeply thankful for her effortless contribution.

\section{References}

Aswin Sangpikul.(2013). Research Methodology for Tourism and Hospitality. Bangkok. Dhurakij Pundit University.

Blancheton, B., \& Marchi, J.-J. (2013). The three systems of rail tourism: French case. Tourism Management Perspectives, 5(0), 31-40.

Caffyn, A. (2009). The Slow Route to New Market. Retrieved 26 February 2014 from website http://www.alisoncaffyn.co.uk/index. php?option=com_content\&task=view\&id=14\&ltemid=32

Chanin Youepet. (2012). The Rapidly of Slow Tourism. Journal THM Quarterly Review 2012 (5), 5-6.

Chondarong Tongsong. (2015). A Concept for Developing Slow Tourism in Thailand. Research Methodology \& Cognitive Science, 12,(2), October 2014 - March 2015.

Cook, Roy A., Laura, J.Y., \& Joseph, J.M. (2010). Tourism: the Business of Travel, 4th edition, New Jereay: Pearson Prentice Hall.

Dickinson, J. E., Robbins, D., \& Lumsdon L. (2010). Holiday travel discourses \& climate change. Journal of Transport Geography, 18(3), 482-489.

Dickinson, J. E., Robbins, D., \& Lumsdon L. (2010). Holiday travel discourses \& climate change. Journal of Transport Geography, 18(3), 482-489.

Dickinson, J. \& Robbins, E., (2008). Representations of tourism transport problem in a rural destination. Tourism Management, 29.11101121

Dickinson, J. \& Lumsdon, L. (2010). Slow Travel and Tourism. Earthscan, London, Washington, DC.

Eisichaikul, R. \& Songsoonthornwong, C. (2012). Learning through Interpretation of European Senior Tourists in Thailand: Slow Tourism Domain. Journal of tourism and Hospitality, 7(1), $41-57$.

Lea, J. (1988). Tourism and Development in the Third World. London: Routledge

Slow Food Association. (2014). About us. Retrieved 27 March 2014 from Slow Food Association website: http//www.slowfood.com/ international/1/about-us.

Lumsdon, L. M., \& McGrath, P. (2011). Developing a conceptual framework for slow travel: a grounded theory approach. Journal of Sustainable Tourism, 19(3), 265-279.

Matos, Rafael. (2004) .Can Slow Tourism Bring New Life to Alpine Regions? In Klaus Welermair \& Christine Mathies (ed), The Tourism \& Leisure Industry: Shaping the Future, New York: Hospitality Press.

Peeter. P. (2007). Mitigating tourism's contribution to climate change - an introduction. In P. Peeter (ed) Tourism and Climate Change Mitigation: Methods, greenhouse gas reductions and policies and policies. Breda: Stitching NHTV Breda, 11-16.

Petrini, C. (2003). Slow food :The case for taste. New York: Columbia University Press.

Robinson, P., Heitman, S., \& Dieke P. (2011). Slow food, slow cities \& slow tourism, Research Themes for tourism. 114-127.

Robinson, P., Heitmann, S., \& Dieke P. U. C. (2011). Research themes for tourism. Wallingford, Oxfordshire ; Cambridge, MA: CABI.

Salvo, P.D. (2013). "Repellent" Tourist versus "Slow" Tourist. European Journal of Tourism, Hospitality \& Recreation, 4(2), 131-148.

Yurtseven, H., \& Kaya, O. (2011). Slow Tourist: A Comparative Research Based on Cittaslow Principle. American International Journal of Contemporary Research, 1(2), 91-98.

World Travel and Tourism Council (WTTC) (2007) The 2007 Travel and Tourism Economic Research. 